\title{
LAS MEDEAS DE CHRISTA WOLF Y ELENA SORIANO, JUNTAS Y EN CONTRASTE
}

THE MEDEAS OF CHRISTA WOLF AND ELENA SORIANO, TOGETHER AND IN CONTRAST

Marcos Román Prieto

Universidad de Sevilla

\section{Resumen:}

El presente estudio comparativo pretende contrastar las reescrituras del mito de Medea de dos obras narrativas: Medea. Stimmen de Christa Wolf y Medea 55 de Elena Soriano. Con sus similitudes y diferencias, y con el personaje mitológico como elemento catalizador, abordan una serie de temas, desde una intimista introspección, con los que pretenden dignificar la figura femenina.

\section{Palabras Clave:}

Christa Wolf, Elena Soriano, Medea, dignificación femenina.

\section{Abstract:}

This comparative study aims to contrast the rewritings of the myth of Medea from two narrative works: Christa Wolf's Medea. Stimmen and Elena Soriano's Medea 55. With their similarities and differences, and with the mythological character as a catalyst, address a range of issues, from an intimate introspection, with those they seek to dignify the female figure.

\section{Keywords:}

Christa Wolf, Elena Soriano, Medea, feminine dignification. 
1. SOBRE LAS AUTORAS E INTRODUCCIÓN A SUS OBRAS. HACIA UNA DESMITIFICACIÓN Y DIGNIFICACIÓN DEL MITO

La escritora española sufre la represión y el exilio interior en la posguerra franquista, mientras que la alemana se siente extranjera ante la nueva situación que representa la reunificación de dos Estados que, si bien comparten una Historia, lengua y cultura comunes, encarnan dos modelos frontalmente opuestos. Inexorablemente impregnan estas dos vidas tan diferentes una huella en la creación narrativa de cada una de estas dos autoras. Ambas son hijas de tiempos difíciles, de países, épocas y culturas opuestas Aunque son coetáneas, no se conocen. No obstante, experimentan un encuentro común: Medea.

Christa Wolf escribe Medea. Stimmen ${ }^{1}$ en 1998, tras un periodo de sequía creadora originada por la persecución de gran parte de la crítica literaria de la Alemania reunificada, desde donde se la acusó de ser escritora afín al establishment dictatorial de la recién extinta República Democrática Alemana. Sin embargo, su oposición a la censura intelectual ejercida por el régimen de Honecker, así como su compromiso en pro de ciertas minorías, víctimas de la represión en la Alemania del Este, se reflejó en toda su carrera literaria. Todo ello se concentra también en la obra que aquí se trata a la que le añade, además, el componente mitológico, convirtiendo al personaje de Medea en un sujeto atemporal, a quien, según sus propias palabras, "aún no se le ha hecho justicia".

Cuarenta años antes, la escritora española, a pesar de ser víctima de la censura franquista, así como de verse relegada por un régimen que no aceptó nunca su carácter universal, feminista y progresista, fue capaz de escribir una gran obra que, aunque fue denostada por gran parte de la crítica contemporánea patriarcal y ultraconservadora, no deja de ser una de las más brillantes aportaciones literarias del Siglo XX en España. Medea 55 fue descrita por la propia Soriano como una "parodia novelesca del mito clásico". Se atrevió a señalar, bajo la máscara del argumento narrativo, que hacía una revisión del mito transponiéndolo en otro lugar, otro tiempo y otros personajes. Su Medea no mata a Glauce, y su peculiar Jasón -encarnado en el personaje de Miguel rechaza al bebé que la protagonista acoge en sus entrañas.

Ambas autoras coinciden en enfocar su necesidad de impartir justicia a la figura femenina a través de la deconstrucción del mito. Para ello, una hace oír sus voces y la otra, sus diálogos. Todo ello sirve para acometer una reconstrucción dignificada de esta figura universal de la Mitología.

1 Traducción del original al español a cargo de Miguel Sáenz, bajo el título de Medea. Publicado en Madrid, en 1986 por la editorial Debate
Si Wolf se sirve de las voces de los personajes principales de la obra para relatar el argumento, Soriano lo hace a través de un narrador omnisciente, que deja espacio también a numerosos diálogos y pensamientos íntimos de los personajes. De un modo $\mathrm{u}$ otro, ambas escritoras pretenden que el lector no se restrinja a la mera función de espectador, sino que se erija en una especie de juez de un proceso que pretende demostrar la inocencia de Medea ante las infames acusaciones con las que la sociedad patriarcal ha estigmatizado su figura. Para este propósito, es necesario que el lector se despoje de antiguos prejuicios y preste atención a testimonios directos, así como a nuevos enfoques, al tiempo que debe participar en la tarea de estudiar antecedentes y reflexionar para, finalmente, intentar imponer justicia

Elena Soriano (1917-1996), española, intelectual y escritora precoz, vio cómo la Guerra Civil trastocó su vida para siempre. No pudo concluir su segunda carrera universitaria, se le arrebató su puesto de funcionaria obtenido con máxima calificación, viéndose forzada a vivir como una esposa y madre dependiente del sueldo de su marido. Pese a que todo ello le causó una enorme frustración, nunca dejó de escribir. Dentro de su trilogía Mujer y Hombre se enmarca su extraordinaria novela Medea 55. En esta obra, Soriano nos presenta a Medea transformada en la actriz española Daniela del Valle, cuya historia vital sirve de punto de partida para tratar tabúes como el de la virginidad, la sexualidad o la infidelidad, así como temas como el de la traición o su deseo de liberación como mujer; todo ello en un tiempo donde el género femenino vivía subyugado en un represivo contexto sociocultural. Parte de su obra, incluida esta trilogía, fue censurada. Elena Soriano, autora de numerosos ensayos y obras clave en la Literatura española, nunca fue reconocida como hubiera merecido. Falleció en 1996 curiosamente el mismo año en que Christa Wolf (1929-2011) publicó Medea. Stimmen.

Ambas estuvieron en contacto con los movimientos y corrientes literarias en los que el elemento femenino adquiría una nueva dimensión que buscaba igualdad y reconocimiento. Ninguna de las dos se consideró a sí misma expresamente feminista. Simplemente necesitaban, a través de sus plumas, equilibrar la balanza de la literatura hacia un enfoque más justo y menos patriarcal. Christa Wolf, en su visita a Barcelona en 1986, donde acudió invitada con motivo de las jornadas «El libro alemán: instrumento de diálogo y cultura con Cataluña», llegó a decir: "No creo que la obra sea feminista, ni yo misma me considero feminista. Ante todo quiero ser realista y estoy en contra de la literatura patriarcal" (Farré, 1986: 57)

Soriano se sentía identificada con autoras tanto de la esfera internacional -Beauvoir Mead, Sagan, Brönte, Friedman-, como del panorama literario español -Pardo Bazán y Rosalía de Castro-. Por su lado, Wolf se alimentó del pensamiento de escritoras como Elisabeth Lenk, Ingeborg Bachman o Anna Seghers, así como de aquellas que habían reflejado en sus obras las heridas de la sociedad patriarcal, como la española 
Mercé Rododera, cuya novela La plaça del Diamant, se incluía entre las obras que más influyeron en la escritora alemana.

Entre Christa Wolf y su Medea -a la que ella denomina la "bárbara del Este"- existe un gran nexo de unión, ya que ambas se sienten extranjeras allá donde vayan. “Ella era para mí la bárbara del Este. Pero entonces sólo conocía la clásica versión que se basaba en Eurípides." ${ }^{2}$ (Hochgeschurz, 1998: 22). Al mismo tiempo, Elena Soriano se lamenta por ser prisionera en su propio país y opta por lo que ella misma denomina un "exilio interior".

Con estas dos obras, ambas escritoras reinterpretan la figura de Medea, de tal modo que pueden reflejar sus inquietudes y sus deseos, cada una desde una perspectiva diferente. Si Christa Wolf elabora una deconstrucción del mito sin separarlo del contexto original mitológico, en la novela de Elena Soriano, la heroína de la Cólquide es trasladada al mundo contemporáneo de 1955. Ambos personajes viven exiliados y arriban, tras una larga travesía en barco y huyendo de sus países de origen, al puerto de un nuevo lugar, en busca de nuevas oportunidades. Medea encuentra, en la obra de Wolf, un reino en el que gobierna un monarca infanticida y un poder corrupto, mientras que en la novela de Soriano, la heroína recala en una nueva tierra llena de oportunidades.

El perfeccionismo es una cualidad que une a las dos autoras, como se desprende del profundo trabajo de investigación y estudio que precedió a la escritura de ambas obras. Con diferentes estilos y enfoques, cada una de ellas, mediante el detalle de la descripción de los acontecimientos y la actuación de los personajes, demuestra la exactitud y el rigor que llevaron a la elaboración de sus Medeas, nacidas fruto de una profunda reflexión y de un intento común de aportar una visión dignificada de la figura mitológica. Ambas autoras enfocan el Mito de una manera más cercana. El hecho de que tanto Soriano como Wolf coincidan en detallar la descripción física y psicológica de los personajes, humanizan y convierte el mito clásico, el cual se torna más accesible. Mientras la escritora alemana enriquece la obra con la inclusión de personajes nuevos, como Leucón, Agameda, Acamante, Presbón, Arinna y Turón, Elena Soriano coloca en su trama al núcleo de los personajes eurípideos, que son transformados, a través de una transposición, en figuras que sólo existen en la ficción narrativa: Daniela del Valle (Medea), Miguel Dargelos (Jasón), misia Alba (Lisa) y la joven sin nombre (Glauce). De manera secundaria, aparecen los personajes de la tía de Daniela -a la que se podría

2 "Sie war für mich die `Barbarin aus dem Osten`. Da kannte ich allerdings nur die gängige Überlieferung, die sich an den Euripides hält." Cita extraída de una carta que Christa Wolf envió a Heide Göttner-Abendroth, desde Santa Mónica (EE.UU.), el 13 de octubre de 1992

3 La Cólquide (también Cólquida) fue un antiguo reino cuya localización se encuentra en la actual Georgia. De all procedía, según la Mitología, Medea y el Vellocino de Oro. identificar con la tía Circe de la Medea mitológica, pues aquí, al contrario que en Wolf ${ }^{4}$ sí es la hermana del padre- y la niña tullida que había sido recogida y hospedada por la familia de la protagonista, la cual nada tiene que ver con la hermana Calcíope de la Medea wolfiana.

\section{Medea y Daniela del V alle}

En el ejercicio de la deconstrucción y reestructuración del mito, Wolf elige partir de la figura clásica, mientras que la escritora española nos presenta a una Medea moderna. No obstante, se acerca más a los principios medeicos de la tradición eurípidea la Daniela del Valle de Soriano. La Medea de Wolf es una mujer de gran fortaleza y seguridad, algo que muchos lo toman como pura arrogancia y, aunque en ciertos momentos de la obra ésta confiesa sentimientos de culpabilidad y añoranza, nunca muestra el menor atisbo de descontrol, desequilibrio o desesperación. A lo sumo, la observamos, ya al final de la obra, sumida en cinismo y dolor, al tiempo que acaba maldiciendo a los culpables de su suerte y de la muerte de sus hijos.

Soriano, en su particular intento de dignificación de la figura mitológica, no termina de suprimir algunas características inherentes a la transmisión tradicional del mito. Su Medea sí exhibe una cierta desesperación e incluso sed de venganza. Daniela del Valle, humillada, se siente insegura por contemplarse a sí misma en plena decadencia física. Se ve postergada al haber sido abandonada por Miguel, del que sigue profundamente enamorada. Su orgullo está herido, a diferencia de la Medea de Wolf, quien tras dejar de amar a Jasón, es capaz de reanudar su vida con Oistros, su nuevo amante. La protagonista de Soriano, en cambio, exhibe un elemento claro de dependencia y obsesión por Miguel. Recuerda la Medea de Soriano a la mitológica en el elemento del sentimiento de injusticia e ingratitud. Se trata de una mujer que lo ha dado todo por su amado y que, al cabo del tiempo, es abandonada por el hombre por quien se sacrificó a lo largo de su vida. Se siente utilizada. Por él ha llegado a menospreciar y abandonar a su propia familia, además de prostituir su dignidad. También, en una transposición metafórica del Vellocino de Oro, Daniela se atreve a hurtar las joyas de la familia para favorecer a su marido. Con todo, al final se ve ahogada en un océano de desagradecimiento y desprecio. Esto provoca un sentimiento de ira y rabia hacia Miguel, que contrasta con la serenidad de su homóloga en la obra de Wolf. La protagonista de Medea. Stimmen posee la suficiente entereza y los resortes psicológicos

4 Conviene señalar que la Circe mitológica, a la que se atribuyen cualidades mágicas, es considerada la tía paterna de Medea. Sin embargo, en el ejercicio de la reescritura del mito, Christa Wolf la presenta como la tía materna. El motivo de esta reinterpretación radica en la creencia por parte de Wolf de que las cualidades de hechicería sólo podían venir por línea materna. 
necesarios para no sentirse dolida por aquellos menosprecios. Todo ello le confiere el empuje para rehacer una nueva vida, libre de odio hacia su esposo.

2.1. HeCHiCERA

En la obra de Wolf, todos los elementos mágicos de la Medea hechicera son presentados de manera racional. Ella simplemente es una sabia que maneja técnicas tanto medicinales como de entrenamiento. Esto explicaría cómo Medea logra engañar a la serpiente que guarda el Vellocino de Oro en la Cólquide, pues era una costumbre propia de esas tierras la de domesticar serpientes. Medea no es hechicera, utiliza sus manos, hierbas y ungüentos medicinales, y lo hace de manera experimentada, como si le viniera heredado por linaje. Tampoco son sus artes infalibles, como demuestra el hecho de que no pueda evitar la muerte de la madre de Agameda. En el proceso de curación de Glauce puede distinguirse claramente cómo Medea utiliza mecanismos similares al psicoanálisis en un proceso lento, con etapas y esfuerzo, y no a través de un golpe de magia. Lo que Christa Wolf pretende con todo ello es desmitificar una mujer que nunca debió ser elevada al mito de la manera en que se llevó a cabo.

En la Medea de Soriano existen elementos que apelan a la magia y hechicería, tales como los bailes de Daniela, aquel perfume que su tía Circe le regaló y que produjo una especie de hechizo en Miguel y los efectos de la propia belleza física de la protagonista. Aunque no dejan de ser elementos subjetivos, Soriano, con la ayuda de la imaginación del lector, trata de reflejar elementos similares a los de la Medea euripídea. En los preparativos de su encuentro con Miguel, Daniela lamenta no conservar aquel perfume que logró hechizar a su amado. Nos preguntamos si Soriano realmente intenta, en su reconstrucción del mito -aun haciendo un guiño al enfoque de la Medea como hechiceradesmitificar lo que tradicionalmente se considera hechicería y encantamiento.

2.2. BAILE MITOLÓGICO Y SACRIFICIO DEL TORO

Existe un paralelismo muy curioso entre ambas autoras a la hora de reflejar la admiración que tanto Jasón como Miguel llegan a sentir por sus respectivas Medea y Daniela.Lo hacen, precisamente, a través de actos simbólicos similares en los que ellos no son más que espectadores, mientras que ellas dirigen un ritual -en Wolf, como sacerdotisa y en Soriano, como bailarina de una ceremonia-. El Jasón wolfiano se siente fascinado ante el rito en el que Medea ejerce de sacerdotisa. Se trata del sacrificio de un toro. La visión del cuerpo de Medea, de sus movimientos en combinación con la sangre, le hace sentir una atracción sexual inaudita, que más tarde rememorará excitado. Durante el baile de Daniela -que parece simbolizar la danza de la diosa
Ártemis ${ }^{5}$ - Jasón se percata de algo que, por lo que se refiere a la caracterización física, es uno de los aspectos que más llama la atención: sus pies. Miguel los odia, evocando así la leyenda de la Dama del pie de cabra, que algunos folkloristas como Prada Samper (2002: 15-23) sitúan como origen del mito de Medea. Por el contrario, en un acto más de deconstrucción del mito, los pies de la Medea de Christa Wolf son los más bellos que Jasón haya visto jamás: “[...] a Jasón le gustan los pies de las mujeres, pero ninguna tiene los pies tan bonitos como yo, que él me volvió a decir"6 (Wolf, 2010: 23).

2.3. LA TIERRA DE ACOGIDA

La escritora alemana nos muestra una Corinto muy diferente de la añorada tierra natal de la heroína. Este enfoque difiere por completo con respecto a la admiración y sentimiento de gratitud que Daniela del Valle siente por el nuevo país de acogida. Si la Medea de Wolf pasa de ser princesa en la Cólquide a una mujer injustamente proscrita y despreciada en Corinto, la Daniela de Soriano alcanza triunfo personal y social en un país que la acoge con los brazos abiertos.

2.4. LA DECADENCIA FísICA

Llama sumamente la atención, y más sabiendo que ninguna autora leyó a la otra, la coincidencia existente entre las obras de Soriano y Wolf, en cuanto a las descripciones de sus Medeas y cómo éstas se realizan desde la misma perspectiva: son descritas por Jasón y Miguel Dargelos -y no el narrador- con la coincidencia de un encuentro visual. Ambos hombres descubren con sorpresa y agrado el atractivo físico de Medea. Tanto Medea como Daniela del Valle son morenas, de cabellera negra abundante -alisada y con bucles en la figura de Soriano y rizada en el caso de Wolf-. La ropa que llevan es de talle ceñido, lo que hace presagiar las bellas formas del esbelto cuerpo.

Elena Soriano utiliza la decadencia física como un argumento muy recurrente y habitual en la sociedad de posguerra española, donde el rol femenino queda relegado al hogar. La mujer no se encuentra en el plano laboral en la misma situación que el hombre y existe una dependencia económica y social de la figura del esposo. Es una época en la que no haber logrado casarse y quedarse soltera se convierte en un estigma. Así lo refleja la autora en su Playa de los locos. ${ }^{7}$ En este contexto, la apariencia física

5 Diosa responsable del fallecimiento de las mujeres. Por otro lado, Hécate es la diosa de la Cólquide y Ártemis es diosa de Corinto. Hécate había sido la diosa de la luna, pero acabó siendo la diosa de las sombras, de los secretos. A ella le ofrecían sacrificios de animales. Por su parte, Ártemis era la diosa de la luz lunar, de la caza y de las noches claras. También era la diosa del templo de Corinto, a la que veneraban con una danza en una ceremonia, colgando los genitales de los toro como símbolo de fertilidad.

6 "[...] daß Jason die Füße der Frauen mag, aber keine habe so schöne Füße wie ich, daß sagte er wieder.”

7 Primer título de su trilogía Mujer y hombre, que se completa con Espeiismos y Medea 55. 
femenina como un símbolo de mayor valoración y respeto por la sociedad machista se convierte en una obsesión y constante para la mujer de la época. No es tan importante parecer sexy, sino evitar a toda costa la decadencia corporal, que implica la connotación de perder la juventud $y$, por ende, la capacidad reproductiva, aspecto vital para la visión teleológica que de la mujer tiene esa cultura patriarcal. A través del personaje de Daniela, Elena Soriano refleja el miedo a la decadencia corporal.

El contexto social que rodea a Christa Wolf es diferente. En dicha sociedad, aun con grandes connotaciones patriarcales, la mujer puede triunfar en campos científicos y literarios con mayor facilidad que en la España franquista. La autora alemana logra ser reconocida en su país, al contrario que Elena Soriano. Por otra parte, cuanto más independiente, económico, social y culturalmente, es una mujer, menor es la atadura que ésta sufre con respecto a la exigencia de su apariencia física. No existe tanta necesidad por competir por ser el mejor objeto de deseo para el hombre.

La Medea de Wolf se siente segura con su apariencia física, se considera aún bastante atractiva aun aceptando que ya no es una mujer joven. Se mira y se recrea en el espejo y se ve a sí misma como una mujer hermosa y madura. Acepta que sus carnes no tienen la lozanía de la juventud, pero las encuentra aún hermosas y acordes para su edad. Como mujer madura, acepta que su cuerpo ha evolucionado y encuentra la gran belleza que aún perdura en ella.

2.5. INFANTICIDIO

La Medea de Soriano, a diferencia de la de Eurípides o Wolf, se siente una madre frustrada, algo de lo que culpa a su esposo. Daniela sufre un aborto natural de un hijo muy deseado por ella -y no por él- en el barco que les lleva hacia el nuevo continente. Los restos del nasciturus son arrojados al mar por el propio Miguel, en una evocación del episodio mitológico de Apsirto ${ }^{8}$. Este hecho parece invertir los papeles y activar el instinto de paternidad de Miguel, mientras que el instinto de maternidad de Daniela se desvanece. Se trata de una característica que puede llegar a ocurrir en relaciones de dependencia obsesiva, como la que la protagonista profesa hacia su esposo.

Daniela sólo tiene una hija viva: Micaela. La Medea de Wolf -a este respecto más fiel a la tradición euripídea- es madre de dos varones: Mérmero y Feres. En la muerte de la niña, no están presentes ni Daniela ni Miguel por motivos de trabajo. Lo mismo ocurre con Mérmero y Feres, quienes en la obra de Wolf mueren lapidados en el templo de Hera, sin la presencia de sus padres. A partir de esta diversidad, se abre una brecha

8 Según fuentes mitológicas griegas, durante el viaje de regreso de los Argonautas, Apsirto fue descuartizado por su hermana Medea, y sus restos arrojados desde el Argos al mar, que posteriormente fueron recogidos uno a uno por su padre aún mayor entre las Medeas de Soriano y de Wolf, que se vuelve más acusada en el asunto de la muerte de los hijos.

La Medea de Wolf ama a sus retoños, intenta protegerlos y maldice a los responsables de haber ocasionado su muerte. Es una mujer fuerte que no quiere separarse de ellos. Sin embargo, la Daniela de Soriano, como mujer débil y vulnerable, siente tal conmoción por el abandono de Miguel, que no se ve capaz de seguir sola con el embarazo, y también lo lamenta: “iHijos míos, hijos míos!”, haciendo alusión no sólo a aquel bebé que nunca nacerá, ni a la fallecida Micaela -que murió por una enfermedad ante la ausencia de sus padres-, sino también a aquel arrojado al mar.

2.6. LA INFIDELIDAD, CELOS Y SENTIMIENTO DE VENGANZA

Daniela del Valle se enamora perdidamente de Miguel Dargelos de una manera posesiva y dependiente. Siente una atracción hacia él que se vuelve enfermiza y salvaje, siguiendo el hilo de la Mitología clásica, donde fue un hechizo de Afrodita lo que provocó el enamoramiento. En la obra de Wolf se invierten los papeles como parte del proceso de deconstrucción del mito. Es Jasón el que se siente más atraído. Sólo más tarde profesará Medea amor hacia él, tras su convivencia a bordo del Argos.

Tanto Daniela como Medea conocen las infidelidades de Miguel y Jasón respectivamente. Esta es una característica común. Ambas mujeres mantienen en este sentido una actitud pasiva y de consentimiento. Sin embargo, hay posturas diametralmente opuestas. Por una parte, Daniela percibe que desde que se convirtió en madre, Miguel no demuestra el mismo deseo sexual que antaño, más aún, éste siente atracción lujuriosa hacia otras mujeres. Todo ello la convierte en una mujer celosa. Esta actitud contrasta con la Medea de Wolf, que evoluciona hasta el punto de no sentir rechazo hacia su esposo. Conoce dichas infidelidades, pero no le afectan, y consigue rehacer su vida a través de otra relación. En el marco de esta inversión del mito, es Jasón el que siente celos cuando sospecha de posibles infidelidades de Medea, lo que desata su rabia cuando tiene por fin constancia de la relación de la colquídea con otro hombre.

La ira y la venganza no son características propias de la Medea wolfiana. A lo sumo, Medea llega a maldecir a los responsables de su destino y de la muerte de sus hijos, pero nunca a Jasón. Lo máximo que llega a reprocharle es el destino que él ha tomado, pero no de una manera beligerante. Y no le sobrarían razones, puesto que es traicionada, humillada, abandonada y violada por él. La Medea de Soriano sí llega a sentir deseos de venganza hacia la actitud de Miguel y así lo profetiza cuando le dice que su novia recibirá su regalo de bodas. Ninguna de las Medeas asesina a la prometida de sus infieles esposos, a diferencia de la tradición euripídea. La reconstrucción del mito que ambas autoras realizan exime de toda culpa a Medea. Daniela vaticina que la 
futura novia recibirá su "regalo de bodas", en un tono amenazante. La Medea de Wolf regala a Glauce su propio vestido de fiesta en un acto de conciliación y cariño entre las dos mujeres, donde se abrazan. Por supuesto, el vestido no está envenenado. Es la propia Glauce la que comete el suicidio debido a que no soporta el ambiente opresor y la mentira e injusticia con la que está condenada a convivir.

En la obra de Elena Soriano, la Glauce sin nombre no fallece, pero se produce una metáfora de la muerte cuando, de mano de Daniela, conoce la verdadera naturaleza del alma de Miguel y comprende quién es su marido y los sentimientos reales que alberga hacia ella. Es un hombre sin escrúpulos, vinculado a otra mujer, que ha sido capaz no sólo de destruir la vida de Daniela, sino la de su último hijo, un embarazo que se fraguó cuando supuestamente ya existía compromiso nupcial con la joven prometida. Daniela mata metafóricamente la inocencia de esta chica. Se produce, por tanto, una especie de muerte en vida que acaba con la ilusión de una joven recién casada.

\section{JASÓN Y Miguel DARgelos}

Los caracteres que conforman la personalidad en Jasón y Miguel, aunque mantienen ciertos rasgos comunes, son muy diferentes entre sí.

Miguel Dargelos posee grandes rasgos de narcisismo patológico y ello se descubre en la novela. A través de diálogos y descripciones se van desgranando los elementos que constituyen psicológicamente el trastorno narcisista. Sin embargo, aunque el Jasón de Wolf mantiene los rasgos de preocupación exacerbada de éxito y poder, no comparte el resto de elementos comunes con dicha personalidad. Muy al contrario, se nos presenta como un personaje débil que necesita, para su propia reafirmación la seguridad y fortaleza de Medea. Jasón se deja llevar por Acamante y Creonte para diseñar su propia carrera de éxito, es demasiado vulnerable, recurre constantemente al mecanismo compensatorio de la autojustificación y carece de empatía. Es por eso que es siempre él quien acude al domicilio de Medea buscando palabras de consuelo por sus propios actos.

Miguel Dargelos es un hombre ambicioso, fuerte, que carece de empatía y se siente seguro en el aspecto sexual, precisamente porque no siente gran dependencia de las mujeres. Para él la sexualidad sólo sirve para desahogar una necesidad física. Por el contrario, el Jasón de Wolf, más empático y sensible, llega a sentirse inferior a Medea y sufre una disfunción sexual al consumar una relación íntima con ella. Se muestra muy afectado por los celos que sufre. Parece haber una cierta identificación entre él y la Daniela del Valle de Soriano. Esto ayudaría a entender el proceso de feminización del Jasón wolfiano, al tiempo que su Medea se presenta con unos rasgos masculinizados.
En ambas obras existe una inversión de la cólera, que ya no está presente en los personajes femeninos, sino en los airados esposos. En la Medea de Wolf, tras la condena al destierro, es Jasón el que corre a casa de Medea buscando un consuelo que necesita para autojustificar su carácter débil y por no haber intercedido en su defensa. La falta de comprensión de Medea hace que éste se revuelva y, lleno de cólera y rabia, la viola. Así, un Jasón cuya característica es la cobardía y la dependencia de su esposa, en un ataque de furia -que nos recuerda a las Medeas euripídea y senequiana-, al no haber conseguido la comprensión habitual de ella, acaba imponiéndose sobre la colquídea de la única forma en la que puede, por medio de la fuerza física, en una clara inversión del mito clásico, donde era Medea la que hacía uso de la fuerza bruta ante un Jasón totalmente pacífico. Miguel Dargelos también siente ira, hasta el punto en que termina gritando a Daniela, lleno de furia, y con ganas de abofetearla.

La ambición de ambos hombres en las dos obras coincide con el Jasón del mito clásico. Ansían el poder y por eso optan por el compromiso con la hija del rey Creonte (en el caso de Soriano, la hija de un político de gran influencia).

El destierro de Medea es un elemento común en la mitología griega, que es reflejado también en Wolf. Por el contrario, Elena Soriano lo elimina, añadiendo un elemento de la sociedad patriarcal: Miguel le ofrece seguir siendo su concubina y mantenerla económicamente gracias a sus influencias.

3.1. LA MISOGINIA

Consideramos que el perfil del Jasón de Wolf no es el del misógino, si bien, desde el principio, el personaje evoluciona hasta el punto de sostener actitudes machistas, que más bien parecen responder a un deseo de pertenencia a la comunidad de Corinto donde las mujeres están sometidas al patriarcado-, que a su propia personalidad. De hecho, Jasón admira a Medea. En el fondo, sigue deseando que ella siga siendo suya y se demuestra desde la escena -en la primera voz- en que ambos mantienen relaciones sexuales. Pero del mismo modo, existen ciertos elementos de misoginia que deben ser tenidos en cuenta, como la violación que sufre Medea por parte de Jasón fruto de la misoginia que el esónida profesa.

Miguel Dargelos manifiesta una clara actitud despectiva con respecto a las mujeres. Desde joven, se sentía acosado por ellas, que lo perseguían. Él, por su parte, nunca siente obsesión por ellas y se burla de los trucos que usan las mujeres para disimular sus defectos. Nunca ha llegado a amar a las mujeres ni intelectual ni personalmente. Como diría Baudelaire, para algunos hombres, la característica de amar a una mujer inteligente supone una forma de homosexualidad. Así, en el caso de Miguel, la mujer es sólo un medio para desahogar sus necesidades naturales. De igual forma que utiliza a Daniela para sus ambiciones políticas, lo hará también con su futura esposa. Es 
un personaje de gran indolencia y falta de empatía hacia el universo femenino. Con respecto al desprecio a la mujer, como elemento congénito del misógino Jasón (Miguel Dargelos), cabe señalar cómo la palabra "puta" aparece en ambas obras, siempre refiriéndose al reproche masculino hacia la naturaleza de la mujer liberada. En Medea. Stimmen, Jasón así la llama cuando tiene conocimiento de su relación con Oistros, a pesar de que él poseía diferentes amantes -pues esta conducta estaba, en su visión machista, reservada sólo a los hombres-. En el caso de Miguel, la primera vez no lo dice él, sino que lo escucha de sus compañeros suyos, refiriéndose a una joven Daniela del Valle que mantiene relaciones con los hombres que desea, hecho que para la sociedad patriarcal resulta deleznable. Más tarde, el mismo Miguel la calificaría como una "ramera", cuando le reprocha que ella, en ocasiones, tuviera que prostituirse, a pesar de que lo hiciera para salvar la vida del propio Miguel.

\section{GLAUCE Y LA JOVEN SIN NOMBRE}

Glauce es dibujada siempre en condiciones de inferioridad, en cuanto atractivo físico, con respecto a la protagonista. Es también una mujer débil, más ingenua y de naturaleza infantil. La Medea wolfiana, que conoce bien a su marido, nota perfectamente cómo Jasón siente repulsa hacia la princesa de Corinto. Él mismo lo reconoce cuando es testigo de los ataques epilépticos de su prometida. Como en la Mitología, este personaje tiene una clara función en el argumento de la obra. Por dicha razón, no tiene importancia en cuanto a la profundidad de su caracterización, aunque Wolf sí le depara más protagonismo. Las dos Glauces simbolizan el resorte o paso clave para la ambición de poder. Christa Wolf parece otorgarle un mayor protagonismo: está presente en varias ocasiones a lo largo de la obra, posee una voz propia y aparece en los monólogos de Medea, Leucón y Jasón. La Glauce de Soriano no tiene ni voz propia ni un nombre. No aparece en la obra hasta el capítulo quinto, que parece estar dedicado por completo a ella. Escuchamos sus pensamientos y la vemos actuar. La escritora española hace una recreación hermosa, sensual y llena de descripciones que parecen extraídas de una historia diferente de la que hasta ahora hemos sido testigos como lectores. La ira, la humillación, la traición, el abandono y la muerte pasan a un plano secundario y reina la descripción rica en detalles, rebosante de luz y alegría. Esta joven sin nombre se encuentra feliz, ilusionada y henchida de placer tras pasar su noche de bodas junto a Miguel. El contraste, en este sentido, con la siempre pesimista y enfermiza Glauce de Wolf, es muy sustancial. Además, esta joven agradece a su padre haberle dado como esposo a Miguel, al contrario que su homóloga wolfiana, quien en sus últimos días de vida siente repudio hacia su padre y Jasón.

Destaca una característica común que comparten ambas escritoras en el final que se le otorga a Glauce, muy diferente de la versión euripídea. Ambos personajes terminan conociendo la verdadera naturaleza de sus esposos. En Wolf termina por comprender la mentira y el crimen sobre el que se asienta Corinto, donde Jasón es un elemento más del entramado del poder de un régimen corrupto. Glauce, que es consciente de que no es amada por Jasón, averigua sus ambiciones y entiende que ella sólo supone un instrumento para las ambiciones del esónida.

En el caso de la recién casada de la novela Medea 55, es a partir del regalo de bodas de Daniela, a través de las fotos, las imágenes de aquella mujer, la relación de ambos, la atracción sexual que mantuvieron -y que ella nunca conoció de Miguel-, la consciencia de la muerte de los hijos de aquel matrimonio, cuando conoce la verdadera alma humana de un hombre ambicioso, egoísta y sin empatía, incapaz de amar. Daniela da, por tanto, una muerte figurada a la ilusión de aquella Glauce desvanecida, escupiéndole la realidad a través de trozos gráficos de su vida que envolverán su cuerpo y simularán el vestido envenenado de la Medea de Eurípides.

\section{LISA Y MISIA ALBA}

En la versión de Soriano, el personaje de Lisa es encarnado por misia Alba, quien, al contrario que la nodriza de la Medea clásica o la Lisa wolfiana, es un personaje con el que Daniela no ha tenido contacto hasta llegar al nuevo país de acogida. Muy pronto, misia Alba adquiere un papel maternal: es la protectora, consejera y confidente de Daniela, pero no es en absoluto una sirvienta de la protagonista. Muy al contrario, Soriano la desvincula de la cotidianidad de Medea. Misia Alba es una mujer independiente, rica y filantrópica, que actúa como mecenas del matrimonio.

La Lisa de Wolf coincide con la de Soriano en el hecho de ser la mujer protectora confidente y sabia consejera de Medea. La autora le sustrae el elemento de servidumbre (nodriza y sirviente) para añadirle el de hermandad, que prevalece por encima del maternal. Es importante resaltar que en un momento determinado de la obra, en el que Medea se encuentra en una situación crucial y difícil, Lisa adquiere el rol materno, repitiendo lo mismo que la madre original de Medea le dijo a su hija mientras le leía de niña las líneas de la mano: que el pecado de Medea era el orgullo. Esta coincidencia transforma el enfoque primario de hermandad de la Lisa wolfiana hacia la adquisición de una proyección maternal.

En la obra de Wolf, además de la experiencia de la huida en el Argos y la vida en Corinto, hay un momento en el que se recrea la coincidencia temporal de Lisa con Jasón. Sucede cuando ésta es testigo de la llegada de él justo antes del destierro de Medea. El encuentro entre ambos es desagradable, Lisa siente repulsa ante Jasón, algo que nos recuerda al sentimiento que misia Alba experimenta hacia Miguel, tanto por su deterioro físico como por haberse convertido en un hombre sin escrúpulos. 
En Medea 55, el lector es testigo de varias coincidencias entre Jasón y la nodriza a través de diferentes analepsis. Ejemplo de ello es la escena de la presentación de los exiliados, al principio de la llegada del matrimonio al nuevo país, momento en que misia Alba intercede para conseguirle un empleo. Durante el transcurso de la obra, misia Alba mantiene un encuentro con él para intentar convencerle de que vuelva con Daniela.

\section{CONCLUSIONES}

Con este estudio se ha procedido a realizar un estudio comparativo entre ambas obras, resaltando similitudes y diferencias, tanto de los personajes como de los símbolos, acontecimientos y reflexiones, partiendo de la clave central: la figura de Medea. Se ha llevado a cabo una observación exhaustiva desde dos prismas diferentes, coincidentes y opuestos, en los que se produce una deconstrucción y reestructuración del mito, que en todo caso, dignifica la historia personal.

\section{REFERENCIAS BIBLIOGRÁFICAS}

Eurípides, Alcestis. Medea. Hipólito (Traducción de Antonio Guzmán Guerra), Madrid Alianza, 2009.

Farré, Adela, "Christa Wolf «El supuesto feminismo de mis obras sólo ha sido una etiqueta>". ABC de Madrid. Internet. 14-11-1986. <http://hemeroteca.abc.es/nav/ Navigate.exe/hemeroteca/madrid/abc/1986/11/14/057.html>

García Gual, C., Introducción a la mitología griega, Madrid, Alianza, 1999.

Graves, R., Los mitos griegos 2, Madrid, Alianza, 1996

Hilzinger, S. (Ed.), Christa Wolf. Essays, Gespräche, Reden, Briefe 1987-2000, Múnich Luchterhand, 2001.

Hilzinger, S., Christa Wolf, Fráncfort del Meno, Suhrkamp, 2007.

Hochgeschurz, M. (Ed.), Christa Wolfs Medea. Voraussetzungen zu einem Text. Mythos und Bild, Berlín, Gerhard Wolf Janus Press, 1988.

Hörnigk, T., Christa Wolf, Berlín, Steidl, 1996.

Prada Samper, J. M. (de), “El mito de Jasón y Medea y el folklore”, en López, A.,

Pociña, A., Medeas, versiones de un mito desde Grecia hasta hoy, Universidad de Granada, 2002, pp. 15-23.

Soler Arteaga, M. J., Elena Soriano. Mujer y ensayo, Sevilla, Arcibel, 2009.

Soriano, E., Espejismos, Madrid, Saturnino Calleja, 1955.

Soriano, E., La playa de los locos, Barcelona, Argos Vergara, 1984

Soriano, E., Medea, Barcelona, Plaza \& Janés, 1985.
Soriano, E., Literatura y vida I. Artículos y ensayos breves, Barcelona, Anthropos, 1992.

Soriano, E., Literatura y vida II. Defensa de la Literatura y otros ensayos, Barcelona, Anthropos, 1993.

Soriano, E., Literatura y vida III. Ensayos, artículos, entrevistas. Revista literaria "El Urogallo", Barcelona, Anthropos, 1994.

Wolf, C., “Brief an Heide Göttner Abendroth vom 13. Oktober 1992®, en Hochgeschurz, M., Christa Wolfs Medea. Voraussetzungen zu einem Text. Mythos und Bild, Berlín, Gerhard Wolf Janus Press, 1998, p. 22.

Wolf, C., Medea (Traducción al español de Medea. Stimmen por Miguel Sáenz), Madrid Debate, 1986.

Wolf, C., Medea. Stimmen, Berlín, Suhrkamp, 2010. 